\title{
Studies of organic acids in millet grain and products of its processing by capillary electrophoresis
}

\author{
Dmitry V. Zipaev ${ }^{1, *}$, Andrey N. Makushin ${ }^{2}$, and Julia G. Kuraeva ${ }^{3}$ \\ ${ }^{1}$ Samara State Technical University, Samara 443100, Russia \\ ${ }^{2}$ Samara State Agrarian University, Kinel 446442, Samara region, Russia \\ ${ }^{3}$ Samara National Research University named after academician S.P. Korolev, Samara 443086, Russia
}

\begin{abstract}
Studying the properties of raw materials during various treatments allows expanding the possibilities of its use in related industries of the food industry due to changes in its chemical composition. This work is devoted to the analysis of the use of the method of capillary electrophoresis to study organic acids in a heat-prone grain of millet and millet malt.
\end{abstract}

\section{Introduction}

The use of various types of grain raw materials in the production of food and beverages is of current importance since the rational and balanced component composition of the human diet is the key to a healthy lifestyle $[1,2]$.

Scientists around the world are continually striving to improve existing technologies and develop new technologies and recipes for food and drinks [3, 4]. The most popular types of plant materials used in fermentation technology are grain crops.

This trend is not accidental, since the chemical composition of crops exposed to thermal effects becomes more accessible to the human body, while the chemical composition of crops does not lose its set of biologically active substances, organic acids, macro- and microelements, which are absorbed by the human body as much as possible, contribute to his healthy life.

Besides, the use of fermentation technologies to obtain a product from grain crops allows you to get a product that helps to prevent many human diseases.

The Middle Volga region is a zone of risky farming, and the cultivation of malting barley with protein content in the grain of less than $12 \%$ is not always possible.

We research an alternative grain raw materials for the production of non-alcoholic beverages to reduce the costs of the brewing industry and the dependence of production on the yield of malting barley in the Volga region, as well as to expand the possibilities of brewing in the region.

Along with the traditional types of cereals in brewing, various cereals are used, one of which is millet.

\section{Materials and methods}

For research, a zoned variety of millet "Zaryana" was selected. This variety was bred at the Volga Research Institute of Breeding and Seed named after P.N. Konstantinova, through multiple individual selections from the population from intricate crosses of two hybrid parents (the maternal form was obtained as a result of 19 consecutive crosses, the paternal form as a result of 22 crosses). The zoned grade of millet "Zaryana" is recommended for cultivation in the Samara region of the Russian Federation.

The zoned grade of millet "Zaryana" is a sanguine variety. The grain is red, densely compressed panicle. Plant height $80-90 \mathrm{~cm}$, tillering is weak. Plants, even in wide-row sowing, are singles talked, due to which the stem and grain are more aligned.

The zoned grade of millet "Zaryana" is characterized by stable grain productivity in different years, according to meteorological conditions. The average grain yield is $2.9 \mathrm{t} / \mathrm{ha}$, which is $240 \mathrm{~kg} / \mathrm{ha}$ higher than the standard.

The mid-season vegetation period of the plant is 70 105 days. Plant height varies from 70 to $100 \mathrm{~cm}$. More resistant to lodging and shedding, resistance to drought at the standard level.

The grain of millet of the variety "Zaryana" is thinfilm. Its filminess is $15.8 \%$. The yield of this cereal is $79.5-83.3 \%, 1.0 \%$ higher than the standard. The color of unpolished grain is bright yellow; the weight of 1000 grains is $8.0-9.9 \mathrm{~g}$. According to all quality parameters, the zoned variety of millet "Zaryana" can be classified as valuable in terms of cereal merits.

The zoned grade of millet "Zaryana" is resistant to the smut of the local population. In the case of artificial infection, the damage did not exceed $4 \%$, and in case of damage to the variety, the indicator was $80 \%$ [5].

\footnotetext{
Corresponding author: dvz7@mail.ru
} 
Reading the grain culture of millet "Zaryana" varieties were used to obtain the malt. It has been scientifically proven that the quality of any product primarily depends on the quality of the feedstock and the optimal production technology.

In this regard, we investigated the initial grain quality indicators of the millet of "Zaryana" variety intended for the production of millet malt. The results of the organoleptic and physicochemical assessment of grain quality are presented in Table 1 and Table 2.

Table 1. The results of the organoleptic evaluation of the grain quality of millet "Zaryana".

\begin{tabular}{|c|l|}
\hline Indicators & \multicolumn{1}{|c|}{ Characteristics } \\
\hline Smell & $\begin{array}{l}\text { Peculiar to a healthy grain of millet, without } \\
\text { mold, malt, musty and other extraneous odors }\end{array}$ \\
\hline Color & $\begin{array}{l}\text { Light brown, characteristic of healthy millet } \\
\text { grain and characteristic of this outhouse - } \\
\text { light brown }\end{array}$ \\
\hline Taste & $\begin{array}{l}\text { Peculiar to healthy millet grain, with a } \\
\text { specific mild taste }\end{array}$ \\
\hline
\end{tabular}

For an organoleptic assessment of the quality of millet "Zaryana", grain intended for the production of good malt was selected. Organoleptic evaluation of the grain quality of millet "Zaryana" showed that this grain has a healthy appearance, without extraneous odors and flavors, the color is light brown, which corresponds to varietal characteristics.

Table 2. Physico-chemical indicators of grain quality millet "Zaryana".

\begin{tabular}{|l|c|c|}
\hline \multicolumn{1}{|c|}{ Indicators } & $\begin{array}{l}\text { The requirements } \\
\text { of GOST 22983-88 } \\
\text { for grain intended } \\
\text { for processing on } \\
\text { malt }\end{array}$ & $\begin{array}{c}\text { Actual } \\
\text { Values }\end{array}$ \\
\hline \multicolumn{1}{|c|}{ Humidity, \% } & no more than 15.0 & 9.6 \\
\hline Mass of 1000 grains, g & not standardized & 9.3 \\
\hline $\begin{array}{l}\text { The content of weed } \\
\text { impurities, \%: } \\
\text { - weed } \\
\text { - grain }\end{array}$ & no more than 3.0 & 0.9 \\
\hline filminess of a grain, \% & not standardized & 1.0 \\
\hline Volumetric weight, g / 1 & not standardized & 777.1 \\
\hline $\begin{array}{l}\text { Energy germination \%, } \\
\text { no less }\end{array}$ & not standardized & 95.0 \\
\hline $\begin{array}{l}\text { Germination ability, \%, } \\
\text { no less }\end{array}$ & 86.0 & 97.0 \\
\hline Infection, ind./kg & $\begin{array}{l}\text { not allowed, except } \\
\text { for ticks not higher } \\
\text { than I degree }\end{array}$ & not \\
\hline
\end{tabular}

According to the physicochemical quality indicators of the grain of millet, "Zaryana," intended for the production of malt corresponded to class 1 of grain.

The grain of millet "Zaryana" is massive - the weight of 1000 seeds is $9.3 \mathrm{~g}$, which is $0.3 \mathrm{~g}$ higher than varietal characteristics, the importance of grain did not exceed $10.0 \%$, bulk density $777.1 \mathrm{~g} / 1$, energy (for $72 \mathrm{~h}$ ) and germination capacity (for $120 \mathrm{~h}$ ) higher than the requirements of regulatory documentation and, accordingly, amounted to $95.0 \%$ and $97.0 \%$.
Millet malt was produced according to the following technology. By sieving the nesting RL-1 with a diameter of 200 at an oscillation frequency of 1 min using a rectangular sieve, impurities were cleaned. These included a passage from a sieve of $1.5 \times 20 \mathrm{~mm}$ and a gathering of a sieve of $2.3 \times 20 \mathrm{~mm}$.

Then, the grain was washed with running water, after which disinfection was carried out. For this operation, we used hydrogen peroxide $\left(\mathrm{H}_{2} \mathrm{O}_{2}\right)$ - pharmacy peroxide $3.0 \%$. After disinfection, the grain was washed with running water 5-6 times to remove residual disinfection solution.

Malting was carried out according to the MEBAK method in a climatic chamber at a temperature of $14.0 \pm$ $0.1{ }^{\circ} \mathrm{C}$ according to the following scheme:

$-5 \mathrm{~h}-$ wet soaking to the moisture of millet grain $46 \%$;

- $19 \mathrm{~h}$ - air pause;

$-4 \mathrm{~h}$ - wet soaking to millet grain moisture $-46 \%$;

$-20 \mathrm{~h}$ - air pause;

$-2 \mathrm{~h}$ - wet soaking to millet grain moisture $-45 \%$.

Before the third wet soaking, the moisture content of millet grain was determined, which amounted to $45 \%$. Soaking and germination were carried out for 7 days (168 h). Pouring with clean water was carried out 2-3 times a day in such a way that for 2-3 days of sowing, the humidity of millet malt, both during cultivation and the finished one, should be $45 \%$.

Watering was stopped -12 hours before seizure to use malt in the next stage. Drying of millet malt was carried out for 16 hours in a drying cabinet of the UT4623 brand at a temperature of $50^{\circ} \mathrm{C}$; at the end of $16 \mathrm{~h}$ of drying at a temperature of $80^{\circ} \mathrm{C}$, they were brought to a malt humidity of $4.0-4.5 \%$.

The obtained millet malt had an inherent smell, without moldy, musty, and other extraneous odors. The color is inherent in the usual grain of millet. The taste is slightly sweet without extraneous flavors, not sour, not bitter.

Physico-chemical indicators of the quality of malt from millet grain are presented in Table 3.

Table 3. Physico-chemical quality indicators of malt from the grain of millet "Zaryana".

\begin{tabular}{|c|c|}
\hline Indicators & Value \\
\hline Humidity,\% 4.1 & 4.1 \\
\hline Weight 1000 grains, g 8.8 & 8.8 \\
\hline Volumetric weight, g / 1 & 502.3 \\
\hline
\end{tabular}

As the studied plant raw materials, millet grain, and millet malt processed at different temperatures were selected.

5 samples were studied:

- Sample I - millet grain (without heat treatment);

- Sample II - millet grain processed at $\mathrm{t}=160^{\circ} \mathrm{C}$;

- Sample III - millet grain processed at $\mathrm{t}=200^{\circ} \mathrm{C}$;

- Sample IV - malt from millet grain processed at $\mathrm{t}=$ $160^{\circ} \mathrm{C}$

- Sample $\mathrm{V}$ - malt from millet grain, processed at $\mathrm{t}=$ $200^{\circ} \mathrm{C}$ 


\section{Methods of the electrophoretic experiment}

The determination of carboxylic acids in raw materials for beer and malt drinks was carried out by the method of capillary electrophoresis using the KAPEL 105M system, the modern of the certified models in the Kapel series. Along with the latest electronic database, the KAPEL 105M system implements complete instrument control, data collection, and processing using its software, and the ability to record the absorption spectra of the components of the analyzed sample during analysis [6].

Preparation of lead electrolyte. In a dry container with a capacity of $15-20 \mathrm{~cm}^{3}, 9.5 \mathrm{~cm}^{3}$ of phosphate buffer solution, $0.1 \mathrm{~cm}^{3}$ of cetyltrimethylammonium bromide solution (CTAB), and $0.5 \mathrm{~cm}^{3}$ of isopropanol were placed. Thoroughly mixed. Immediately after mixing, the solution was filtered through a membrane filter into a plastic vessel with a lockable lid. A phosphate buffer solution was prepared from a sodium hydrogen phosphate solution (6.73 g of disubstituted 12aqueous sodium phosphate was placed in a $100 \mathrm{ml}$ volumetric flask and dissolved in $50 \mathrm{~cm}^{3}$ of distilled water, then adjusted to the mark with distilled water) and sodium dihydrogen phosphate (placed in a $100 \mathrm{ml}$ volumetric flask $1.56 \mathrm{~g}$ of sodium phosphate monosubstituted 2-water and dissolved in $50 \mathrm{~cm}^{3}$ of distilled water, then brought to the mark with distilled water). First, $50 \mathrm{~cm}^{3}$ of sodium hydrogen phosphate was added to a volumetric flask with a capacity of $100 \mathrm{~cm}^{3}$, then $5 \mathrm{~cm}^{3}$ of sodium dihydrogen phosphate was added, and the mark was distilled with distilled water. A solution of cetyltrimethylammonium bromide was prepared by placing $0.091 \mathrm{~g}$ of CTAB in a volumetric flask with a capacity of $25 \mathrm{~cm}^{3}$ and adding $15 \mathrm{~cm}^{3}$ of distilled water after the complete dissolution was adjusted to the mark with distilled water.

Preparation of individual acid solutions. In a volumetric flask with a capacity of $25 \mathrm{~cm}^{3}$, weighed the corresponding component (Table 4).

Table 4. Recommended weights for the preparation of individual solutions.

\begin{tabular}{|c|c|c|c|}
\hline Weighing form & $\begin{array}{c}\text { Hitch, } \\
\mathbf{m g}\end{array}$ & $\begin{array}{c}\text { Form for the } \\
\text { determination }\end{array}$ & $\begin{array}{c}\mathbf{C}_{\mathbf{h}}^{\mathbf{h}} \\
\mathbf{\mathbf { m g } /} \\
\mathbf{\mathbf { d m } ^ { \mathbf { 3 } }}\end{array}$ \\
\hline Sodium oxalate 38 & 38.0 & Oxalic acid & 1000 \\
\hline Fumaric Acid & 25.0 & Fumaric Acid & 1000 \\
\hline Succinic acid & 25.0 & Succinic acid & 1000 \\
\hline Malic acid & 25.0 & Malic acid & 1000 \\
\hline Citric Acid & 25.0 & Citric Acid & 1000 \\
\hline Lithium Lactate & 54.0 & Lactic Acid & 2000 \\
\hline Sodium Benzoate & 30.0 & Benzoic acid & 1000 \\
\hline Potassium Sorbate & 34.0 & Sorbic acid & 1000 \\
\hline
\end{tabular}

\section{Preparation of calibration mixture}

Preparation of calibration mixture № 1: acid solutions in the following volumes were placed in a vial with a capacity of $15-20 \mathrm{~cm}^{3}$ : oxalic acid $-1.2 \mathrm{~cm}^{3}$, fumaric acid $-0.2 \mathrm{~cm}^{3}$, succinic acid, malic acid, citric acid $-2.0 \mathrm{~cm}^{3}$, lactic acid $-2.4 \mathrm{~cm}^{3}$, benzoic acid -0.2 $\mathrm{cm}^{3}$, sorbic acid $-1.0 \mathrm{~cm}^{3}$ and thoroughly mixed.

Preparation of calibration mixture № 2: $1 \mathrm{~cm}^{3}$ of calibration mixture No. 1 was placed in a dry vial with a capacity of $10-12 \mathrm{~cm}^{3}$, and $4 \mathrm{~cm}^{3}$ of distilled water was added and thoroughly mixed.

Preparation of calibration mixture № $3: 2.5 \mathrm{~cm}^{3}$ of calibration mixture № 1 was placed in a volumetric flask with a capacity of $50 \mathrm{~cm}^{3}$, adjusted to the mark with distilled water and thoroughly mixed (Table 5) [7, 8].

Table 5. Mass concentrations of components of calibration mixtures $\left(\mathrm{mg} / \mathrm{dm}^{3}\right)$.

\begin{tabular}{|l|c|c|c|c|}
\hline \multirow{2}{*}{ Acid Name } & \multicolumn{4}{|c|}{$\begin{array}{c}\text { Mass concentration of components, } \\
\text { mg / dm }\end{array}$} \\
\cline { 2 - 4 } & \multicolumn{3}{|c|}{ Calibration mixtures } & Control \\
& № 1 & № 2 & № 3 & mixture \\
\hline Oxalic acid & 60.0 & 12.0 & 3.0 & 30.0 \\
\hline Fumaric Acid & 10.0 & 2.0 & 0.5 & 5.0 \\
\hline Succinic acid & 100.0 & 20.0 & 5.0 & 50.0 \\
\hline Malic acid & 100.0 & 20.0 & 5.0 & 50.0 \\
\hline Citric Acid & 100.0 & 20.0 & 5.0 & 50.0 \\
\hline Lactic Acid & 240.0 & 48.0 & 12.0 & 120.0 \\
\hline Benzoic acid & 10.0 & 2.0 & 0.5 & 5.0 \\
\hline Sorbic acid & 50.0 & 10.0 & 2.5 & 25.0 \\
\hline
\end{tabular}

Sample preparation of samples of plant materials

Samples of millet and millet malt were pre-crushed using a laboratory mill. Then, weighed portions of prepared malt samples weighing $1000 \mathrm{mg}$ were placed in a flat-bottomed flask with a capacity of $50 \mathrm{~cm}^{3}, 30-40$ $\mathrm{cm}^{3}$ of distilled water with a temperature of $70 \pm 2{ }^{\circ} \mathrm{C}$ were added and stirred for $10 \mathrm{~min}$ with constant heating on a magnetic stirrer. After that, the mixture was transferred to a volumetric flask with a capacity of 50 $\mathrm{cm}^{3}$, the mixture was cooled, and its volume was brought up to a control mark by adding distilled water. The resulting mixture was thoroughly mixed and filtered first through a paper filter and then through a "Vladipor" membrane filter, discarding the first portions of the filtrate.

Analysis of prepared samples. $1.0 \mathrm{~cm}^{3}$ of prepared samples were placed in dry Eppendorf tubes, centrifuged for $5 \mathrm{~min}$ at a centrifuge speed of $5000 \mathrm{rpm}$, and three electropherograms were recorded for each grain sample using the Kapel 105M brand capillary electrophoresis system. At the end of the analysis, the correctness of the automatic peak marking was checked. Using the Elforan software, we identified organic acids (oxalic, fumaric, malic, succinic, citric, lactic, benzoic, sorbic acids) in the test sample by the coincidence of the migration times of the components in the sample and the control mixture with an identification window width of 5\% [9].

\section{Results and discussion}

In the study, five samples of plant material based on millet were studied:

I. Millet grain without heat treatment (taken as a control);

II. Millet grain processed at a temperature of $160^{\circ} \mathrm{C}$; 
III. Millet grain processed at $200^{\circ} \mathrm{C}$;

IV. Millet malt processed at $160^{\circ} \mathrm{C}$;

V. Millet malt processed at $200^{\circ} \mathrm{C}$.

Figure 1 shows the electropherogram (EFG) of sample I, a control grain sample.

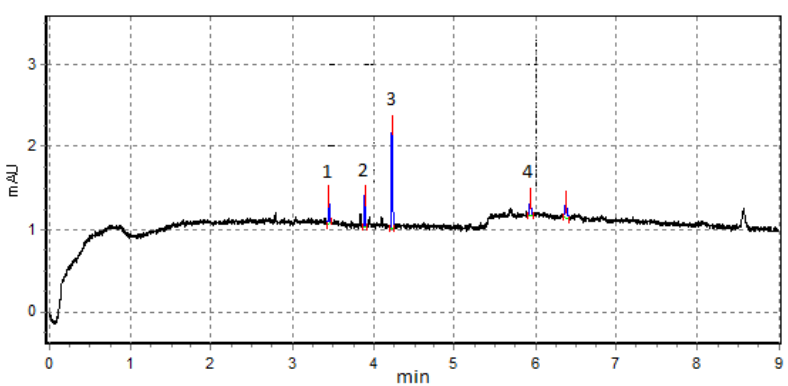

Figure 1. Electrophoregram of sample I. Capillary $50 \mu \mathrm{m} \times 40$ $\mathrm{cm}$; phosphate buffer solution + CTAB + isopropanol; $190 \mathrm{~nm}$; $20^{\circ} \mathrm{C} ;-17 \mathrm{kV}: 1$ - oxalic acid; 2 - fumaric acid; 3 - citric acid; 4 - sorbic acid.

From the obtained EFG, it is seen that in the sample of millet grain, which was not subjected to malting and heat treatment, the content of four organic acids, namely oxalic acid, fumaric acid, citric acid, and sorbic acid, was found. The electropherogram of samples II and III, which are millet grains, subjected to heat treatment at $160^{\circ} \mathrm{C}$ and $200^{\circ} \mathrm{C}$, respectively, are shown in Figure 2 .
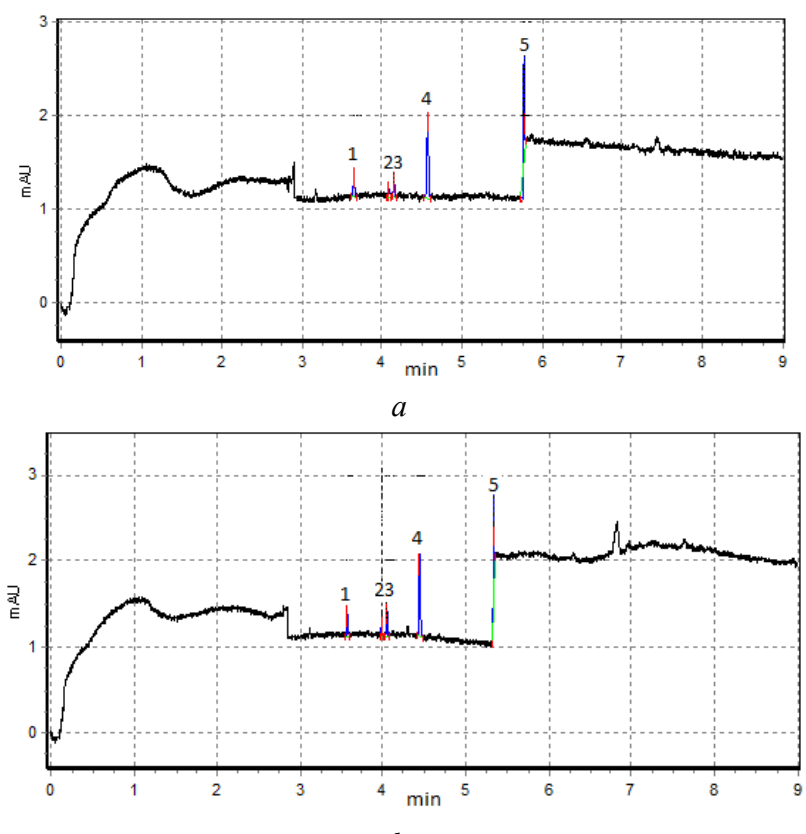

$b$

Figure 2. Electrophoregrams: $a$ - sample II: 1 - oxalic acid; 2 fumaric acid; 3 - succinic acid; 4 - citric acid; 5 - benzoic acid; $b$ - sample III: 1 - oxalic acid; 2 - fumaric acid; 3 - succinic acid; 4 - citric acid; 5 - benzoic acid. Capillary $50 \mu \mathrm{m} \times 40 \mathrm{~cm}$; phosphate buffer solution $+\mathrm{CTAB}+$ isopropanol; $190 \mathrm{~nm} ; 20^{\circ}$ $\mathrm{C} ;-17 \mathrm{kV}$.

According to the data obtained, heat treatment changes the acid composition of the grain; in addition to oxalic, fumaric, citric, and sorbic acids, succinic acid appears. Electrophoregrams of samples II and III, which underwent different heat treatments, are similar, but not identical. Figure 3 and Figure 4 show electropherograms of malt samples that underwent heat treatment.

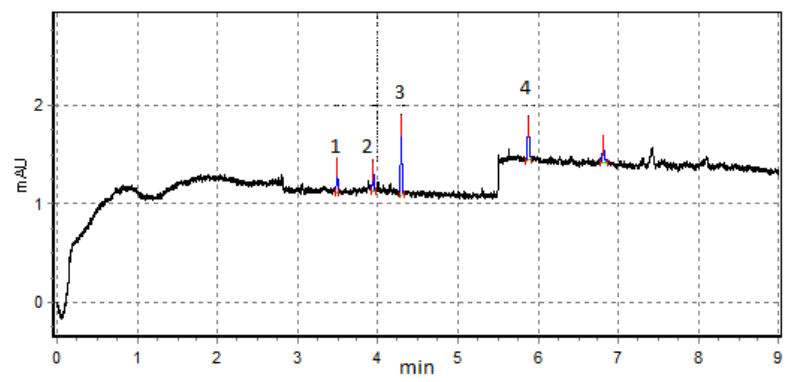

Figure 3. Electrophoregram of sample IV. Capillary $50 \mu \mathrm{m} \times$ $40 \mathrm{~cm}$; phosphate buffer solution + CTAB + isopropanol; 190 $\mathrm{nm} ; 20^{\circ} \mathrm{C} ;-17 \mathrm{kV}: 1$ - oxalic acid; 2 - fumaric acid; 3 - citric acid; 4 - sorbic acid.

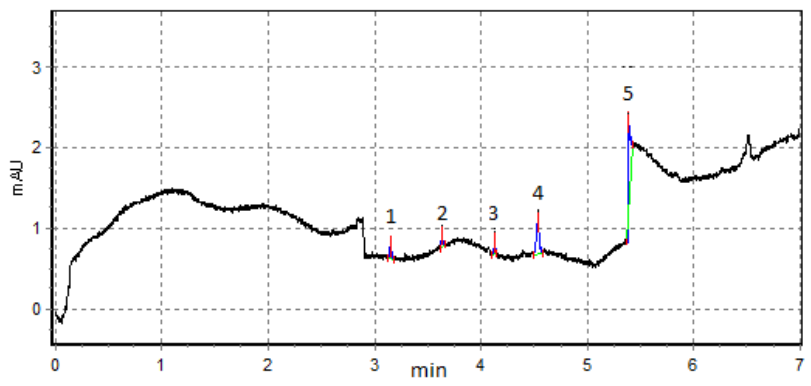

Figure 4. Electrophoregram of sample V. Capillary $50 \mu \mathrm{m} \times$ $40 \mathrm{~cm}$; phosphate buffer solution + CTAB + isopropanol; 190 $\mathrm{nm}, 20^{\circ} \mathrm{C},-17 \mathrm{kV}: 1$ - oxalic acid; 2 - fumaric acid; 3 - citric acid; 4 - lactic acid; 5 - benzoic acid.

Samples IV and V, sprouted grain and heat-treated significantly differ from each other in acid composition. Thus, oxalic, fumaric, citric and sorbic acids were found in sample IV, and oxalic, fumaric, citric and benzoic acids were found in sample $\mathrm{V}$.

The quantitative content of organic acids in the test samples is presented in Table 6. The concentrations shown in Table 6 are the average values of their 3-5 experimentally obtained results.

Table 6. Experimentally determined concentrations of organic acids (mg / 1$)$.

\begin{tabular}{|c|c|c|c|c|c|c|c|c|}
\hline Acid & 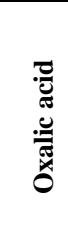 & 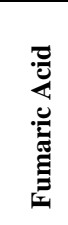 & 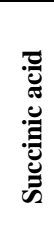 & 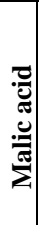 & 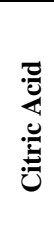 & 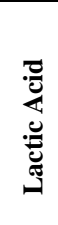 & 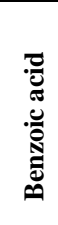 & 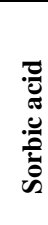 \\
\hline Sample I & 0.25 & 0.26 & - & - & 2.5 & - & - & 0.1 \\
\hline Sample II & 0.24 & 0.09 & 0.4 & - & 2.2 & - & 0.2 & - \\
\hline $\begin{array}{l}\text { Sample } \\
\text { III }\end{array}$ & 0.21 & 0.22 & 0.8 & - & 2.2 & - & 0.1 & - \\
\hline $\begin{array}{l}\text { Sample } \\
\text { IV }\end{array}$ & 0.21 & 0.14 & - & - & 1.4 & - & - & 0.3 \\
\hline $\begin{array}{l}\text { Sample } \\
\text { V }\end{array}$ & 0.23 & 0.12 & - & - & 0.6 & 0.6 & 0.6 & - \\
\hline
\end{tabular}


The obtained content of organic acids in the studied samples of plant materials for the production of beer and malt drinks varies significantly. So oxalic, fumaric, and citric acids are fixed in all five samples of grain, both after only heat treatment, and sprouted. Succinic and benzoic acids appear in grain samples II and III, which underwent heat treatment, but sorbic acid disappears in comparison with the control sample I.

Table 7 presents the content of organic acids in $1 \mathrm{~g}$ of a dry sample of plant material, expressed in $\mathrm{mg}$.

Table 7. The content of organic acids ( $\mathrm{mg}$ ) in $1 \mathrm{~g}$ of a dry sample of plant material

\begin{tabular}{|c|c|c|c|c|c|c|c|c|}
\hline Sample & 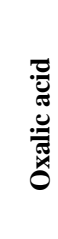 & 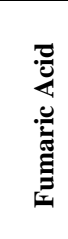 & 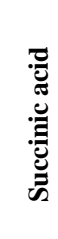 & 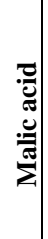 & 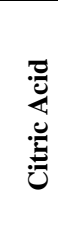 & 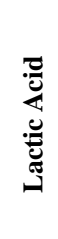 & 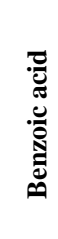 & 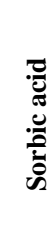 \\
\hline $\begin{array}{l}\text { Sample } \\
\text { I }\end{array}$ & 0.01 & 0.013 & - & - & 0.13 & - & - & 0.01 \\
\hline $\begin{array}{l}\text { Sample } \\
\text { II }\end{array}$ & 0.01 & 0.004 & 0.02 & - & 0.09 & - & 0.01 & - \\
\hline $\begin{array}{l}\text { Sample } \\
\text { III }\end{array}$ & 0.01 & 0.011 & 0.04 & - & 0.13 & - & 0.01 & - \\
\hline $\begin{array}{l}\text { Sample } \\
\text { IV }\end{array}$ & 0.01 & 0.007 & - & - & 0.07 & - & - & 0.02 \\
\hline $\begin{array}{l}\text { Sample } \\
\text { V }\end{array}$ & 0.01 & 0.006 & - & - & 0.03 & 0.03 & 0.03 & - \\
\hline
\end{tabular}

We compared the content of oxalic acid in the studied samples of plant materials based on millet. The amount of oxalic acid is comparable for all samples. Oxalic acid is formed during the hydrolysis of oxalicacetic acid in the Krebs cycle and practically does not change as a result of biochemical processes during germination.

When assessing the concentration of fumaric acid in the studied raw materials, it can be seen that the biochemical processes that occur during germination significantly reduce its content (by 48-54\%). Besides, the concentration of fumaric acid in the malt is influenced by chemical processes that occur during the drying of the malt. It is at this stage of the process that fumaric acid is oxidized. Similarly, the process of germination of millet grain leads to a decrease in the content of citric acid (by 46-76\%). Interestingly, the thermal treatment of grain leads to the appearance of succinic acid, as well as benzoic.

Conducted studies on the determination of organic acids in the grain raw materials of millet and its processed products have shown that by the quantitative content and ratio of acids it is possible to judge the naturalness and quality of the beverages made, as well as to control the enzymatic processes in the production and processing of raw materials.

\section{Conclusion}

The article researched the determination of organic acids by capillary electrophoresis in grain raw materials for beer production. Five samples of millet that underwent the process of germination and/or various heat treatment were examined. Based on the studies, the following conclusions can be drawn:

1. Different samples of millet and malt grains contain different organic acids.

2. Biochemical processes during malting and heat treatment of grain raw materials lead not only to quantitative changes in the acid composition but also to qualitative ones.

3. By the quantitative content and ratio of acids, it is possible to judge the naturalness and quality of the manufactured drinks and to control technological processes.

\section{References}

1. V. Thapliyal, K. Singh, Finger millet: potential millet for food security and power house of nutrients Int. J. of Research in Agriculture and Forestry 2, 22-33 (2015)

2. S. Rathore, K. Singh, V. Kumar, Millet Grain Processing, Utilization and Its Role in Health Promotion: A Review Int. J. of Nutrition and Food Sciences 5(5), 318-329 (2016)

3. A. M. Dias-Martinsa, K. L. F. Pessanha, S. Pacheco, J. A. S. Rodrigues, C. W. P. Carvalho, Potential use of pearl millet (Pennisetum glaucum (L.) R. Br.) in Brazil: food security, processing, health benefits and nutritional products Food Research Int. 109, 175186 (2018)

4. E. S. Chauhan, Sarita Effects of Processing (Germination and Popping) on the Nutritional and Anti-nutritional Properties of Finger Millet (Eleusine coracana) Current Research in Nutrition and Food Science 6(2), 566-572 (2018)

5. M.I. Dulov, A.V. Volkova, A.N. Makushin, Productivity and grain quality of millet in the Volga region (RICA of the State Agricultural Academy, Samara, 2013)

6. L. Ferey, N. Delaunay, Food analysis on electrophoretic microchips Separation \& Purification Reviews 45, 193-226 (2015)

7. M. Wang, F. Qu, X.Q. Shan, J.M. Lin, Development and optimization of a method for the analysis of low-molecular-mass organic acids in plants by capillary electrophoresis with indirect $U V$ detection J. of Chromatography A 989(2), 285-292 (2003)

8. S. Rovio, K. Sirén, H. Sirén, Application of capillary electrophoresis to determine metal cations, anions, organic acids, and carbohydrates in some Pinot Noir red wines Food Chemistry 124(3), 1194-1200 (2011)

9. M 04-47-2012 Method for measuring the mass concentration of organic acids and their salts by capillary electrophoresis (Lumex, Moscow, 2012) 